\title{
Analysis of Effect of the Socio Economic Status on Prevalence of Overweight and Obesity Among School Going Student in India
}

\author{
Priyanka Sachdewa and Shubham Mohan Sharma \\ Department of Community Medicine Shree Guru Gobind Singh \\ Tricentary University, Gurugram, Haryana, India \\ Corresponding author email: shubham_fmhs@sgtuniversity.org
}

\begin{abstract}
Obesity and overweight has become a serious health issue worldwide and require some medical intervention to overcome this problem. It has been found that an unhealthy lifestyle is a major cause of obesity worldwide. The problem of obesity and overweight has become a serious health threat to the children because of their habit in the technologically advanced world. The current study has been done on the student of age group between the 9 to 16 years. The corporation and private school have been selected for the study in the Delhi, Capital of India. The main basis for the study is the socio economic back ground of the student as the student with Lower socio economic status (LSES) have been studied in corporation school generally and on the other hand, student with upper socio economic status have studied in the private school where fee structure is quite high in comparison to corporation school .In the study, it had been found that the life style of the student is the main input to make them obese and overweight.
\end{abstract}

KEY WORDS: CHILDHOOD OBESITY, ADOLESCENTS, DEPRESSION, SOCIOECONOMIC STATUS, SCHOOL CHILDREN.

\section{INTRODUCTION}

With 210 million school-age children worldwide classified as overweight / obese, obesity has emerged as one of the major health issues, of which 50-60 million are obese. Increased intake of high-calorie foods that are poor in vitamins, minerals and micronutrients, combined with reduced physical activity, are the factors due to increased childhood obesity (J. G. Vaamonde et. al. (2020)) Various studies conducted in India from 2002-2019 suggest an growing trend in children and adolescents in the prevalence of overweight and obesity. This may have important consequences for increasing the prevalence of early

Biosc Biotech Res Comm P-ISSN: 0974-6455 E-ISSN: 2321-4007

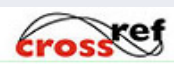

Identifiers and Pagination

Year: 2021 Vol: 14 No (6) Special Issue

Pages: $390-394$

This is an open access article under Creative

Commons License Attribn 4.0 Intl (CC-BY).

DOI: $h t t p: / / d x . d o i . o r g / 10.21786 / b b r c / 14.7 .82$ adulthood non-communicable diseases (NCDs) such as diabetes, hypertension, and cardiovascular disease.

Obesity is generally associated with lifestyle issues more than the hereditary in some families. As technology has become more and more advanced, humans become lazier and, in addition to this, dietary habits also turn towards junk food rather than healthy food. In both developed and developing countries, the prevalence of obesity is growing at an unprecedented pace worldwide. In this age group, the growing number of obese children and adolescents worldwide calls for intervention in primary and secondary prevention of overweight and obesity. During infancy and the teenage years, most people grow their eating and behavior habits. The changes in diet and behaviors caused by the prevalence of fast foods, soft drinks, and sedentary lifestyle, lack of exercise, and increased watching television and computer use may be the triggers of overweight in richest and poorest children (S. R. Daniels et. al. (2016).

Obesity is a dynamic, chronic disease characterized by different causes and adverse health effects. It is well known, however, that not all people with the same degree of obesity

\section{Article Information}

Received: 17 May 2021

ccepted after revision: $29^{\text {th }}$ July 2021 
have similar health risks. One unique obesity subtype of concern, called metabolically healthy obesity, is distinct in that individuals comply with the clinical concept of obesity, but because of their elevated levels of fatness, they do not demonstrate typical cardio metabolic risk factors. There are desirable cardio metabolic profiles for individuals with $\mathrm{MHO}$ that are usually characterized by normal blood pressure, serum lipids, insulin and glucose, liver enzymes, and hormonal profiles (WHO et. al. (2016)). The present paper has been written on the basis of a study conducted among the school going students to find out the effect of obesity as per their socio economic status and other factors.

Review Of Literature: Rajesh Sagar et al. studied that childhood body fat is associated with many physical health risks and many evidence regarding this also mentioned in the paper. The most adverse condition is when the obesity of an individual is associated with one's mental health and this is a concern of the researchers as well as clinical trials. A variety of psycho-social difficulties are faced by obese children that greatly affect quality of life and well-being. In general, co-morbid psychosocial and emotional obesity issues serve as causal or maintenance causes for obesity and thus have a direct influence on the result of treatment. Therefore, in the clinical analysis of childhood obesity, it is important for clinicians / pediatricians to extend their clinical review to include evaluation of significant psychosocial factors. The obesity problems of the children must be addressed with proper medical and lifestyle changes intervention.

However, during this process of weight loss a lot of hurdles have been seen such as families, personal and environmental (R. Sagar et. al. (2018). Chika Okada et al have revealed that obesity and overweight of the people have become a serious problem worldwide in this technology dependent world. The problem has become more serious if it has been found since the childhood of an individual and it may lead to serious medical problems such as high blood pressure and asthma. The prevalence of obesity worldwide has been found to be as high as 10 percent so far and still it is continuously counted more per year. Some researchers found that to overcome the problem of obesity, it is necessary to observe the dietary behavior from the start of one's childhood. It has been seen that childhood obesity is generally related with the skipped breakfast habit. There is a lack of longitudinal relationship information regarding parents and children skipping meals, especially for children below 5 years of age. In addition, the link between missing breakfast and the risk of child obesity has been ambiguous in previous studies. (C. O. et. al. (2018). A. Kobes et al revealed in his paper that the epidemic of child and adolescent obesity has been a significant worldwide problem.

Numerous programs focused on raising the weight status of children have been launched to avoid the rise in the number of young people with overweight / obesity. Several meta-analyses attempting to provide an overview of the efficacy of treatments have summarized the growing body of research on weight-related treatments for adolescents. Yet, the number of meta-analyses is increasing too rapidly and aggregate findings vary, making it difficult to comprehensively summarize the literature. A metasynthesis was performed to discuss this topic and draw educated conclusions about the state of the efficacy of approaches targeting overweight children and adolescents. Childhood obesity should be addressed by urging children and teenagers to consume fewer sugar-containing and fatcontaining foods and exercise more, but this is easier said than done (Y. Yang et. al. (2018).

\section{METHODOLOGY}

Design: An analysis has been designed to investigate the school going children in India. For the analysis, students between the age group 9 to 16 years have been selected, the logic behind this selection of the group is that too young children were not able to cooperate during the questionnaire session and children above 16 years age have undergone many psychological and physical changes. Therefore, selected age group of 9 to 16 is the most appropriate for the study and theses children have studied in the grade of IV to $\mathrm{X}$. the more essential criteria to select the student is their socioeconomic background as children have categorized into two groups on the basis of the social and economic status (N. K. Güngör et. al. (2014).

India is a developing country and there is a huge difference between the per capita income within a group and on the basis of the income of the families, a categorization of the families has been done as low income group, medium income group and high income group. These different income groups have the capabilities to get admission of their wards as per their income and capability to pay of the fees of the school. Therefore, a categorization of the school also has been done as the corporation school, where fees for the student is less and second one is the private school ,where fee is more than the corporation school and fees ranges in private schools varies from the 5000 to 50000 Rs per annum.

Figure 1: Pattern of the School in India

Types of School Private School Aided School Corporation/government School

Sample: The age group of the children have been divided into categories as the first group comprises the student from the age group of the 9 to 12 years (Children) and second group is the 12 to 16 years (adolescent). An ethical permission has been taken from the ethics committee of each school before getting the children a part of this survey. The Delhi, a metropolitan city and capital of the India, has been selected for the survey, where three type of the school have been existed, first one is municipal corporation school, second one is the state government school and third one is the private school with high fee structure .For the purpose 
of the survey 10 student have selected from each school and 5 school have selected from each category. The pattern of the school in India has been shown in Figure 1.

Instrument: The instrument depends upon the type of the queries asked in the questionnaire and depends upon the socio and demographic variation of the children along with anthropometric measurements. The anthropometric measurements comprise the height, weight and waist circumference of the children. The children have asked the question on diabetes, obesity, their diet plan, number of hours spent before the TV and on mobile phones and their indulgence in their physical activities. To evaluate the responses a scale with the range 1-50 have incorporated. After evaluation of the response, a regression technique has been implemented to find out the final result of the research.

Data collection: For the data collection, a lecture has been conducted for the student in each school to make them aware about the survey and its importance so that they will take it seriously and respond honestly (K. B Smith et. al. (2016). A well designed questionnaire has been circulated to all students and for this, printed papers containing 40 questions have been given to all and they have asked to complete it in a stipulated time. All the responses of the children have evaluated on the scale of the 0 - 50 and evaluated accordingly. The data had been collected over the period of the 2018 to 2019.

Data Analysis: The data was analyzed using SPSS version 12 Statistical software. The prevalence rate with obesity as well as obesity was estimated on the basis of the BMI and cut-off values as described above. For anthropometric measurements, the analysis of variance (SD) was measured. Chi square work was carried out to assess the importance of proportions. To evaluate the variables associated with obesity, numerous logistic regressions were performed. The data as collected in the survey have been analyzed and given in the form of the Table below. Table 1 has shown the prevalence data of obesity and overweight and Table 2 is showing the Anthropometric Measurements of School Children.

Table 1. Age and Gender Specific Prevalence of Overweight and Obesity Table 1. Distribution

\begin{tabular}{|c|c|c|c|c|c|c|c|c|}
\hline \multirow[t]{4}{*}{ Condition } & \multicolumn{4}{|c|}{ LSES } & \multicolumn{4}{|c|}{ USES } \\
\hline & \multicolumn{2}{|c|}{ Children } & \multicolumn{2}{|c|}{ Adolescents } & \multicolumn{2}{|c|}{ Children } & \multicolumn{2}{|c|}{ Adolescents } \\
\hline & Boys & Girls & Boys & Girls & Boys & Girls & Boys & Girls \\
\hline & $\mathrm{n}=93$ & $\mathrm{n}=87$ & $\mathrm{n}=45$ & $\mathrm{n}=43$ & $\mathrm{n}=292$ & $\mathrm{n}=233$ & $\mathrm{n}=232$ & $\mathrm{n}=176$ \\
\hline \multirow[t]{2}{*}{ Overweight } & 10 & 9 & 3 & 5 & 30 & 40 & 32 & 40 \\
\hline & 10.2 & 9.5 & 4.9 & 8.6 & 8.6 & 17.6 & 14.5 & 22.0 \\
\hline \multirow[t]{2}{*}{ Obese } & 5 & 3 & & 1 & 29 & 30 & 20 & 21 \\
\hline & 5.1 & 3.1 & & 2.6 & 10.9 & 12.5 & 9.2 & 11.3 \\
\hline
\end{tabular}

Table 2. Mean and SD Values Of Anthropometric Measurements of School Children From Lower And Upper Socioeconomic Status

\begin{tabular}{|c|c|c|c|c|c|c|c|c|}
\hline & \multicolumn{4}{|c|}{ Children } & \multicolumn{4}{c|}{ Adolescents } \\
\hline & \multicolumn{4}{|c|}{ (age 9-12 years) } & \multicolumn{3}{c|}{ (age 13 -16 years) } \\
\hline & \multicolumn{2}{|c|}{ Boys } & \multicolumn{2}{c|}{ Girls } & \multicolumn{3}{c|}{ Boys } & \multicolumn{2}{c|}{ Girls } \\
\hline & LSES & USES & LSES & USES & LSES & USES & LSES & USES \\
\hline & & & & & & & & \\
\hline Height & 138.3 & 142.3 & 139.1 & 135.4 & 154.0 & 153.1 & 153.3 & 168 \\
$(\mathrm{~cm})$ & \pm 8.2 & \pm 9.3 & \pm 9.8 & \pm 9.2 & \pm 10.3 & \pm 9.1 & \pm 5.1 & \pm 7.0 \\
\hline Weight & 30.7 & 34.4 & 31.2 & 40.4 & 47.2 & 44.2 & 44.5 & 53.4 \\
(Kg) & \pm 7.3 & \pm 9.3 & \pm 8.1 & \pm 10.4 & \pm 11.0 & \pm 11.4 & \pm 9.5 & \pm 11.4 \\
\hline BMI & 15.2 & 15.2 & 15.1 & 18.3 & 14.4 & 17.0 & 18.4 & 20.2 \\
(Kg/m2) & \pm 2.7 & \pm 3.5 & \pm 2.6 & \pm 2.3 & \pm 2.1 & \pm 3.2 & \pm 3.2 & \pm 4.2 \\
\hline WC & 53.4 & 62.4 & 54.1 & 54.5 & 63.3 & 57.4 & 52 & 56.4 \\
$(\mathrm{~cm})$ & \pm 8.6 & \pm 9.7 & \pm 7.3 & \pm 4.3 & \pm 4.3 & \pm 5.6 & \pm 5.3 & \pm 7.5 \\
\hline
\end{tabular}

Where BMI Body Mass Index; LSES= Low socio economic status; USES = Upper Socio economic status

RESULTS AND DISCUSSION

$\overline{\text { According to the analysis of the data, } 12.1 \text { percentages of }}$ the children are overweight in the age group of the 9 to 12 year of age and 16.4 percentages of children have been reported overweight among the age group of the 13 to 16 years. The tendency of the overweight and obesity are seen 
higher in the girls in comparison to the boys and this is little bit higher in the adolescence. Significant differences have been reported between the low and high social economic status. The implementation of regression analysis revealed that the obesity problem is prevalent among the students who are used to watching TV more than 2 hours(A. Afshin et. al. (2017)). The use of the TV is more frequent in the higher age group of the adolescent and consequently, this effect has been seen in this age group with more cases of overweight and obesity.

Figure 2: Waist size and ages of the LSES and USES students

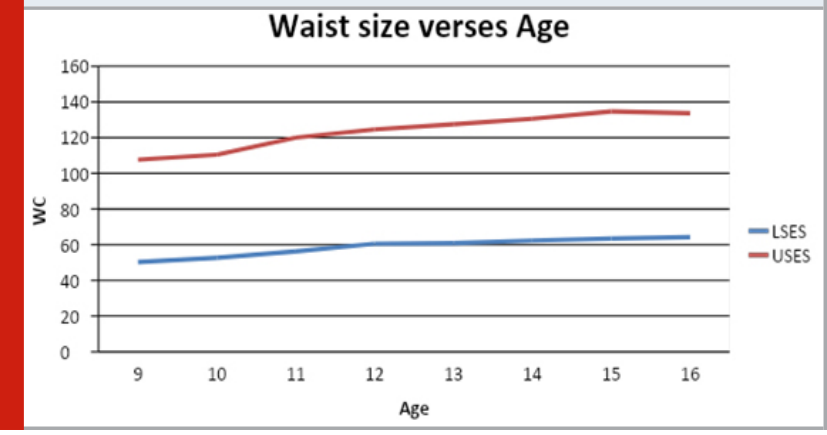

The study also found one more interesting fact that when the data of this study has compared with the results of the past study then, it is found that the obesity problem is more prevalent in the children of this current study than the past study. The upper class girls are more affected with the obesity problem because of their eating habits. Our research has shown higher statistics that are representative of the 21 st century obesity crisis. Figure 2 has shown the difference between the waist size of the both the socio economic status students.

Figure 3: BMI and Age of the LSES and USES Students $\mathrm{BMI}$ verses Age

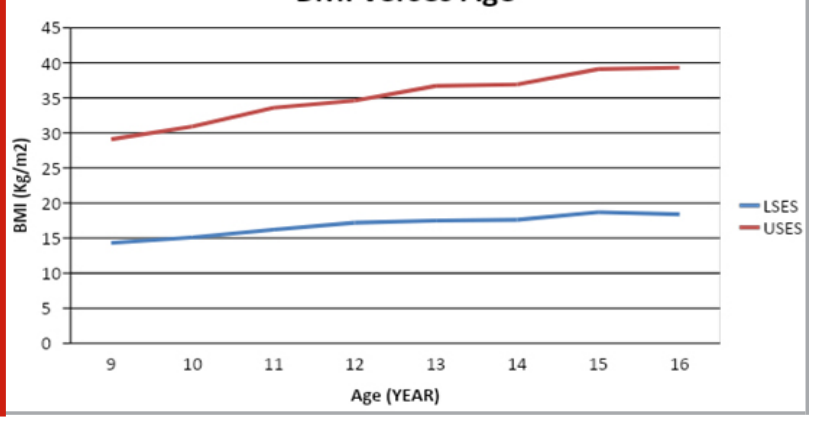

The socioeconomic effect on the prevalence of overweight and obesity is yet another observation of this study. The prevalence in the upper social status of overweight and obesity was substantially higher. Compared with the normal WHO 2007 reference maps, the mean values of BMI and waist circumference for subjects drop below the 50th percentile. We therefore infer that overweight and obesity are in USES more than that. Such findings indicate agreement with findings from other Indian studies (K. M. fock et. al. (2013)). The female gender had a higher overweight preponderance and was more common in USES.
However, puberty and growth spurts for girls occurring at an earlier age can have a conflicting impact. The number of adipose tissue cells has been reported to increase throughout these times, followed by a slowing after puberty. Figure 3 has shown the data of the BMI and age of the students.

The study revealed that unhealthy lifestyle patterns are common. India is currently experiencing a rapid epidemiological transformation, with a direct effect on eating habits and lifestyles. An area of concern is the rise of fast-food outlets and the quick availability of junk food. Kids today prefer fruits and veggies to these foods. In our research, as all these food products were easily accessible in their college cafeteria, we reported that kids from charter colleges ingested more fast food items including carbonated beverages. In order to collect comprehensive feedback on the status or quantity of food intake, eating behavior and evaluate its connection with information beyond the scope of this report, further research is needed. While the participants were well educated about the strong athletic activity results, we found that they're not engaging in physical activity on a regular basis. Just 30 percent of children who are overweight had at least a few minutes of daily physical activity, which is reflective of the younger generation's poor diet.

The new trend is that school kids are more focused on academics and less interested in types of activities. Leisure years were spent watching TV or playing computer / video games, thus illustrating today's school children's sedentary lifestyle. Such results have been associated with other research (T. Lehnert et. al. (2013)). To summaries, our findings indicate that child obesity is on the increase, especially amongst wealthy urban children, and there is very poor awareness of lifestyle-related conditions such as hypertension and obesity as well as their prevention. Besides that, attention has to be paid to the prevalence of unsafe habits among adolescents. The health effect of the growing prevalence of obesity as well as obesity among children and teens is a matter of great concern. In the past century, diabetes and high blood pressure were rare among children and young adults. But these illnesses, supposed to be illnesses of the aged, often occur in the younger generation today.

\section{CONCLUUSION}

Childhood obesity has arisen as a danger to children and adolescents' physical and mental health. It can be inferred, based on the mixed outcomes of research, that not all obese children encounter psychosocial problems. Some particular groups were found to be at risk of developing comorbid psychological disorders, such as young women, clinical obesity groups, and children with serious and persistent obesity. It is, however, imperative that each and every obese child and adolescent be screened for. Our findings indicate that the obesity epidemic is on the rise, especially among prosperous urban children, and there is very poor awareness of lifestyle-related diseases such as obesity and diabetes and their prevention. Moreover, attention must be paid to the prevalence of unsafe habits among children. The health effect of the growing prevalence of obesity 
including obesity among children and teens is a matter of serious concern.

\section{REFERENCES}

Fock, K.M. and Khoo, J., 2013. Diet and exercise in management of obesity and overweight. Journal of gastroenterology and hepatology, 28, pp.59-63.

GBD 2015 Obesity Collaborators, 2017. Health effects of overweight and obesity in 195 countries over 25 years. New England Journal of Medicine, 377(1), pp.13-27.

Lehnert, T., Sonntag, D., Konnopka, A., Riedel-Heller, S. and König, H.H., 2013. Economic costs of overweight and obesity. Best practice \& research Clinical endocrinology \& metabolism, 27(2), pp.105-115.

Okada, C., Tabuchi, T. and Iso, H., 2018. Association between skipping breakfast in parents and children and childhood overweight/obesity among children: a nationwide 10.5-year prospective study in Japan. International Journal of Obesity, 42(10), pp.1724-1732.

Sagar, R. and Gupta, T., 2018. Psychological aspects of obesity in children and adolescents. The Indian Journal of Pediatrics, 85(7), pp.554-559.

Smith, K.B. and Smith, M.S., 2016. Obesity statistics. Primary care: clinics in office practice, 43(1), pp.121135.

Stein, J., Bennett, D., Coen, C., Dunbar, R., Goodwin, G., Husain, M., Mann, E., Morris, J., Rolls, E., Taylor, J.S. and Walsh, V., 2016. The curated reference collection in neuroscience and biobehavioral psychology.

Vaamonde, J.G. and Álvarez-Món, M.A., 2020. Obesidad y sobrepeso. Medicine-Programa de Formación Médica Continuada Acreditado, 13(14), pp.767-776.

WHO, "Obesity and overweight: Fact sheet," WHO Media Cent., 2016.

Yang, Y., Shafi, M., Song, X. and Yang, R., 2018. Preservation of cultural heritage embodied in traditional crafts in the developing countries. A case study of Pakistani handicraft industry. Sustainability, 10(5), p.1336.

Güngör, N.K., 2014. Overweight and obesity in children and adolescents. Journal of clinical research in pediatric endocrinology, 6(3), p.129. 